\title{
STRATEGI SINKRONISASI IMPLEMENTASI SISTEM PENJAMINAN MUTU INTERNAL (SPMI) DENGAN ISO 9001 PROGRAM SARJANA IPB
}

\author{
THE IMPLEMENTATION OF INTERNAL QUALITY ASSURANCE SYSTEM (SPMI) \\ WITH ISO 9001 SYNCHRONIZATION STRATEGY \\ (A CASE STUDY OF UNDERGRADUATE PROGRAM OF IPB)
}

\author{
Gigih Budiarto $^{* 1}$, Fredinan Yulianda ${ }^{* *}$, dan Nimmi Zulbainarni $\left.{ }^{* * *}\right)$ \\ ") Departemen Sains Komunikasi dan Pengembangan Masyarakat, Fakultas Ekologi Manusia, Institut Pertanian Bogor \\ Jl. Kamper, Kampus IPB Darmaga, Bogor 16680 \\ ${ }^{* *}$ Departemen Manajemen Sumberdaya Perairan, Fakultas Perikanan, Institut Pertanian Bogor \\ Jl. Agatis Kampus IPB Darmaga, Bogor 16680 \\ ${ }^{* * *}$ Sekolah Bisnis, Institut Pertanian Bogor \\ Jl. Raya Pajajaran, Bogor 16151
}

\begin{abstract}
The objectives of this research were to 1) review the implementation of ISO 9001 management system with internal quality assurance system (SPMI) to support SPME BAN-PT and 2) develop ISO 9001 management system synchronization strategy with SPMI to support SPME BAN-PT. The method used in this research was analytic hierarchy process (AHP). The results show that SPMI and ISO 9001 are running separately. The causal variables include the work unit which has not figured out that the clause in ISO 9001 actually supports the clause of SPMI. Therefore, in implementing the process in accordance with ISO 9001, the target nature is standardization on SPMI. In compiling the ISO 9001 and SPMI system synchronization, a table of conformity between the SPMI and ISO 9001 clauses is established. In reference to the table of conformity, it can be seen that what has been done in the ISO 9001 clause can explain that its implementation supports the achievement of SPMI standard targets related to the corresponding clause. Referring to additional input from the experts on the priority of synchronization strategy of both quality management systems (SMM), it will support the implementation of SPME BAN$P T$ so that the accreditation achievement of leading study program and institution can be achieved efficiently and effectively.
\end{abstract}

Keywords: ISO 9001, SPMI, integrated quality management system, synchronization, AHP

\begin{abstract}
Abstrak: Penelitian ini bertujuan 1) mengkaji pelaksanaan sistem manajemen ISO 9001 dengan sistem penjaminan mutu internal (SPMI) untuk menunjang SPME BAN-PT dan 2) menyusun strategi sinkronisasi sistem manajemen ISO 9001 dengan SPMI untuk menunjang SPME BANPT. Metode yang digunakan pada penelitian ini dengan proses hirarki analitik (AHP). Hasilnya menunjukkan bahwa SPMI dan ISO 9001 berjalan terpisah. Variabel penyebab diantaranya adalah unit kerja belum memahami bahwa klausul pada ISO 9001 sebenarnya menunjang klausul SPMI, sehingga pada pelaksanaan prosesnya sesuai ISO 9001, hakikat target adalah standarisasi pada SPMI. Dalam menyusun sinkronisasi sistem ISO 9001 dan SPMI maka dibuat tabel kesesuaian antara klausul SPMI dengan ISO 9001. Dari tabel kesesuaian terlihat bahwa apa yang telah dijalankan pada klausul ISO 9001 dapat diklaim bahwa pelaksanaannya menunjang pencapaian target standar SPMI terkait klausul yang berkesesuaian. Ditambah masukan dari para pakar tentang prioritas strategi sinkronisasi kedua sistem manajemen mutu (SMM) tersebut akan menunjang pula pelaksanaan SPME BAN-PT sehingga pencapaian akreditasi unggul program studi dan institusi dapat teraih dengan efisien dan efektif.
\end{abstract}

Kata kunci: ISO 9001, SPMI, integrasi sistem manajemen mutu, sinkronisasi, AHP

\footnotetext{
${ }^{1}$ Alamat Korespondensi:

Email: realgigih@gmail.com
} 


\section{PENDAHULUAN}

Tujuan dari Sistem Penjaminan Mutu Pendidikan Tinggi (SPM Dikti) adalah untuk menjamin pemenuhan standar Dikti secara sistemik dan berkelanjutan, sehingga tumbuh dan berkembang budaya mutu di setiap perguruan tinggi di Indonesia. Setiap pendidikan tinggi dapat meningkatkan mutu pendidikannya dengan menerapkan Evaluasi Mutu Internal Perguruan Tinggi (EMI-PT) secara kontinu, sehingga mutu yang sudah dicapai dapat terlihat, dan apabila dilakukan perbaikan maka akan terjadi continuous improvement. Dengan adanya peningkatan mutu perguruan tinggi maka akan memperkuat daya saing perguruan tinggi, terutama dalam menghadapai masyarakat ekonomi ASEAN (Panday, 2014).

Kebijakan pengembangan Sistem Penjaminan Mutu Internal (SPMI) Institut Pertanian Bogor (IPB) tertuang pada statuta IPB pada Peraturan Pemerintah (PP) No. 66 Tahun 2013 Pasal 83. Dalam PP tersebut mengamanahkan IPB untuk mengembangkan sistem penjaminan mutu sesuai dengan ketentuan peraturan perundang-undangan. Penjaminan mutu dilaksanakan secara sistemik, terencana, dan berkelanjutan untuk meningkatkan mutu pendidikan. Penjaminan mutu tersebut dilakukan melalui penetapan, pelaksanaan, evaluasi, pengendalian, dan peningkatan Standar Nasional Pendidikan Tinggi (SNPT), yang secara periodik dievaluasiuntuk diperbaiki. Sistem penjaminan mutu tersebut mengacu pada SPM Dikti dan SNPT.

Kardoyo (2011) berpendapat bahwa mutu pendidikan di Perguruan Tinggi (PT) akan lebih terjamin jika memiliki SPM Dikti yang baik dan kokoh, dapat mengintegrasikan visi, misi dan tujuan-tujuan PT ke dalam visi, misi dan tujuan-tujuan pribadi para pimpinan dan anggota organisasinya. Sivaram et al. (2013) juga mengatakan bahwa total productive maintenance dan sertifikasi International Organization for Standardization (ISO) 9001 sudah diadopsi secara global. Mekić dan Göksu (2014) membuktikan melalui penelitiannya bahwa penggabungan penerapan akreditasi dan ISO 9001 mampu meningkatkan kinerja perguruan tinggi di Bosnia dan Herzegovina.

Asy'ari (2015) mengatakan bahwa perubahanperubahan yang telah terjadi sebagai akibat implementasi sistem penjaminan mutu ISO sudah dirasakan oleh sivitas akademika. Selain itu perubahan juga mampu menampilkan diri dengan praktek nilai- nilai positif yakni sikap dan perilaku yang berorientasi "best practice, customer satisfaction, excellence services, dan continual quality improvement". Umiyati (2015) mengemukakan pendapat bahwa semakin baik tingkat pemahaman dan kesadaran dalam penerapan sistem manajemen mutu (SMM) ISO 9001:2008 yang dilakukan oleh setiap pimpinan, dosen dan karyawan, maka semakin baik pula kinerja mereka. Menguatkan dua pendapat sebelumnya Muafi dan Nilmawati (2014) menyebutkan bahwa penerapan sistem manajemen mutu berpengaruh positif dan signifikan terhadap komitmen organisasional, yang berarti semakin meningkatnya upaya penerapan SMM, maka semakin meningkatkan pula komitmen organisasional.

Purwanti et al. (2015) menyebutkan bahwa manfaat yang diperoleh menggunakan SMM ISO 9001:2008 yaitu seluruh kegiatan telah terstruktur dan tersistem dengan baik (quality improvement) dan sebagai pengevaluasi dan pengontrol kinerja sehingga sebagai upaya pencegahan agar kesalahan yang serupa tidak terjadi lagi. Menurut Pillay dan Kimber (2009), dalam era transnasional dan pasar penyediaan PT, sangat penting untuk memastikan kualitas PT dengan berfokus kepada siapa saja yang dilayani dan penjaminan mutunya. Manajemen mutu di bidang pendidikan adalah satu model pengelolaan pendidikan dalam upaya reformasi pendidikan menuntut adanya dukungan dari stakeholder. Agar PT memiliki standar baku yang ditetapkan organisasi internasional, PT yang telah memiliki kriteria tertentu dimungkinkan untuk dapat memperoleh sertifikasi ISO (Hendartho, 2014).

Sumber daya manusia (SDM), komitmen, motivasi dan reward merupakan variabel penunjang terhadap kinerja auditor. Khususnya bagi auditor internal yang direkrut dari dosen dan tenaga kependidikan, karena mereka harus meluangkan waktu di luar tugas rutinnya. Palupi et al. (2017), menyebutkan bahwa pelatihan fungsional auditor dapat meningkatkan kompetensi auditor yang mencakup aspek pengetahuan (knowledge), ketrampilan (skill) dan sikap prilaku (attitude) agar auditor dapat melakukan tugas-tugas fungsionalnya dengan baik.

Audit internal dibutuhkan untuk menilai akuntabilitas dan kepatuhan manajemen terhadap kebijakan dan peraturan yang berlaku untuk kepentingan para pemangku kepentingan. Hal ini pun perlu dilakukan dalam PT agar dapat menghasilkan ekonomisasi, efisiensi dan efektifitas. Kinerja unggul dicirikan oleh pekerjaan yang efektif dan efisien. Unsur utama 
tercapainya keefektifan suatu pekerjaan adalah mutu hasil. Efektif berarti ukuran keberhasilan dalam memilih dan mencapai tujuan yang tepat diungkapkan dengan "doing the right things". Efisien berarti untuk mencapai tujuan yang telah ditentukan dengan biaya atau sumberdaya minimum diungkapkan dengan "doing things right". Diperlukan pula komitmen pimpinan, karena untuk mengubah paradigma dan sikap mental, serta pengorganisasian penjaminan mutu yang baik dibutuhkan komitmen pimpinan. Tanpa komitmen pimpinan semua hal yang sudah dirancang tidak akan ada gunanya (Gumiandari, 2013).

Evaluasi penting dilakukan untuk memperoleh gambaran mengenai SMM ISO 9001:2008 yang berkualitas. Perolehan sertifikat ISO 9001:2008 tidak terbatas hanya pada administrasi belaka akan tetapi lebih kepada penerapannya pada organisasi. Indeks Kepatuhan Terbobot (IKT) di IPB yang diperoleh dengan menghitung rata-rata capaian pemenuhan standar di bidang akademik dan tingkat kepatuhan unit kerja di bidang keuangan, sumberdaya dan aset. IKT program studi dan unit kerja tahun 2016 mencapai $83,13 \%$ dari target $100 \%$. Belum tercapainya target IKT tersebut disebabkan oleh adanya unit kerja yang belum memahami tentang SPMI, prosedur operasional baku (POB) dan Peraturan Rektor maupun peraturan perundangan yang terkait dengan tata kelola.

Berdasarkan perumusan masalah tersebut maka tujuan penelitian ini adalah 1) Mengkaji pelaksanaan sistem manajemen ISO 9001 dengan SPMI untuk menunjang SPME BAN-PT, dan 2) Menyusun strategi sinkronisasi sistem manajemen ISO 9001 dengan SPMI untuk menunjang SPME BAN-PT. Penelitian ini difokuskan pada program sarjana pada unit Departemen dan Fakultas di IPB, khususnya yang rutin dilakukan audit SPMI dan ISO 9001 dengan studi kasus pada Fakultas Ekologi Manusia (FEMA) IPB.

\section{METODE PENELITIAN}

Penelitian dilaksanakan di Fakultas Ekologi Manusia (FEMA) IPB pada bulan Maret-Mei 2017. Jenis dan sumber data yang digunakan di dalam penelitian ini terdiri dari data primer yang diperoleh langsung dari responden melalui kuesioner oleh para pakar meliputi: Konsultan ISO 9001, Dekan/Mantan Kepala Kantor Manajemen Mutu (KMM) IPB, Kepala Kopertis III, Ketua Gugus Penjamin Mutu (GPM) FEMA IPB dan
Ketua Auditor Internal ISO 9001 FEMA IPB. Data sekunder diperoleh dari beberapa unit kerja di IPB, diantaranya adalah FEMA, Departemen di lingkungan FEMA dan KMM berupa renstra, SWOT, sasaran mutu, manual mutu, dan lainnya. Serta informasi lainnya diperoleh dengan studi pustaka yaitu dengan cara mempelajari dan memahami buku-buku dan jurnaljurnal yang berkaitan dengan teori dan praktik yang digunakan dalam penelitian, serta penelitian terdahulu yang berkaitan dengan topik penelitian ini.

Pengolahan data awal adalah dengan menganalisa SWOT IPB dan FEMA IPB yang mendukung penjaminan mutu dan dibuat pula tabel sinkronisasi keterkaitan antara klausul SPMI dengan klausul ISO 9001. Selanjutnya dari kedua pengolahan tersebut menjadi bahan untuk pembuatan strategi sinkronisasi implementasi SMM SPMI dan ISO 9001 dengan mengolah data kuesioner yang telah diisi oleh para pakar di bidang penjaminan mutu. Metode yang sesuai dengan konsep strategi adalah Analytic Hierarchy Process (AHP).

Pada penerapan metode AHP yang diutamakan adalah kualitas data dari responden, dan tidak tergantung pada kuantitasnya. Penilaian AHP memerlukan pakar sebagai responden dalam pengambilan keputusan dalam pemilihan alternatif. Para pakar disini merupakan orang-orang kompeten yang benar-benar menguasai, memengaruhi pengambilan kebijakan atau benarbenar mengetahui informasi yang dibutuhkan. Untuk jumlah responden dalam metode AHP tidak memiliki perumusan tertentu, namun hanya ada batas minimum yaitu dua orang responden (Saaty, 1993). AHP memiliki banyak keunggulan dalam menjelaskan proses pengambilan keputusan karena dapat digambarkan secara grafis, sehingga mudah dipahami oleh semua pihak yang terlibat dalam pengambilan keputusan tersebut. Dalam penelitian ini pengambilan keputusan menggunakan teknik AHP dilakukan menggunakan software Expert Choice yang dibuat oleh Saaty dan Ernest Forman.

AHP adalah teori pengukuran melalui perbandingan berpasangan dan bergantung pada penilaian dari ahli untuk mendapatkan skala prioritas. Penilaian mungkin tidak konsisten, dan bagaimana mengukur inkonsistensi dan meningkatkan penilaian, bila mungkin untuk mendapatkan konsistensi yang lebih baik diutamakan dalam AHP (Saaty, 2008). Faktor-faktor yang memengaruhi pelaksanaan SPMI dan metode proses 
sertifikasi dan surveilance ISO 9001:2008 di bidang akademik dan non akademik dianalisis menggunakan metode AHP. Solusi yang diharapkan dari metode ini adalah berupa hierarki faktor-faktor yang berpengaruh terhadap pelaksanaan SPMI dan sistem penjaminan mutu ISO 9001 yang efektif dan efisien. Berdasarkan skala prioritas, dipilih faktor-faktor dengan nilai terbesar ke nilai yang lebih rendah. Selain itu juga dicari alternatif strategi untuk mengoptimalkan pelaksanaan SPMI dan sistem penjaminan mutu ISO 9001 berdasarkan skala prioritas dengan memfokuskan kepada kegiatan audit, dikarenakan kegiatan audit sangat mendukung evaluasi siklus SMM.

AHP digunakan untuk menganalisis faktor-faktor yang berpengaruh dalam strategi sinkronisasi implementasi SPMI dengan ISO 9001 program sarjana IPB. Alternatif strategi yang optimal dapat ditentukan dengan cara menelaah elemen faktor yang menjadi kendala, dan yang membuat percepatan akselerasi impelementasi sinkronisasi, begitu pula dengan elemen aktor dan tujuan. Kerangka pemikiran penelitian selengkapnya terlihat pada Gambar 1.

\section{HASIL}

\section{Pengkajian Pelaksanaan Sistem Manajemen ISO 9001 dengan SPMI untuk Menunjang SPME BAN- PT}

ISO-9001:2008 lebih menekankan pada kestabilan proses pengelolaan pendidikan dari waktu ke waktu, sedangkan Badan Akreditasi Nasional Perguruan Tinggi (BAN-PT) lebih menekankan pada hasil akhir dari suatu proses pengelolaan pendidikan. Sehingga bila SMM tersebut diintegrasikan akan menjadi sebuah SMM yang tidak hanya fokus pada kestabilan proses pengelolaan tetapi juga pada kestabilan hasil akhir yang baik. Berdasarkan pendekatan proses dan kebutuhan dokumentasi SMM ISO 9001:2008 dan BAN-PT, kerangka proses SMM terintegrasi suatu Program Studi/Perguruan Tinggi dapat dikategorikan terdiri dari empat proses utama yaitu proses komitmen manajemen, proses inti, proses manajemen mutu, dan proses pengelolaan sumberdaya (Luthfi, 2011)

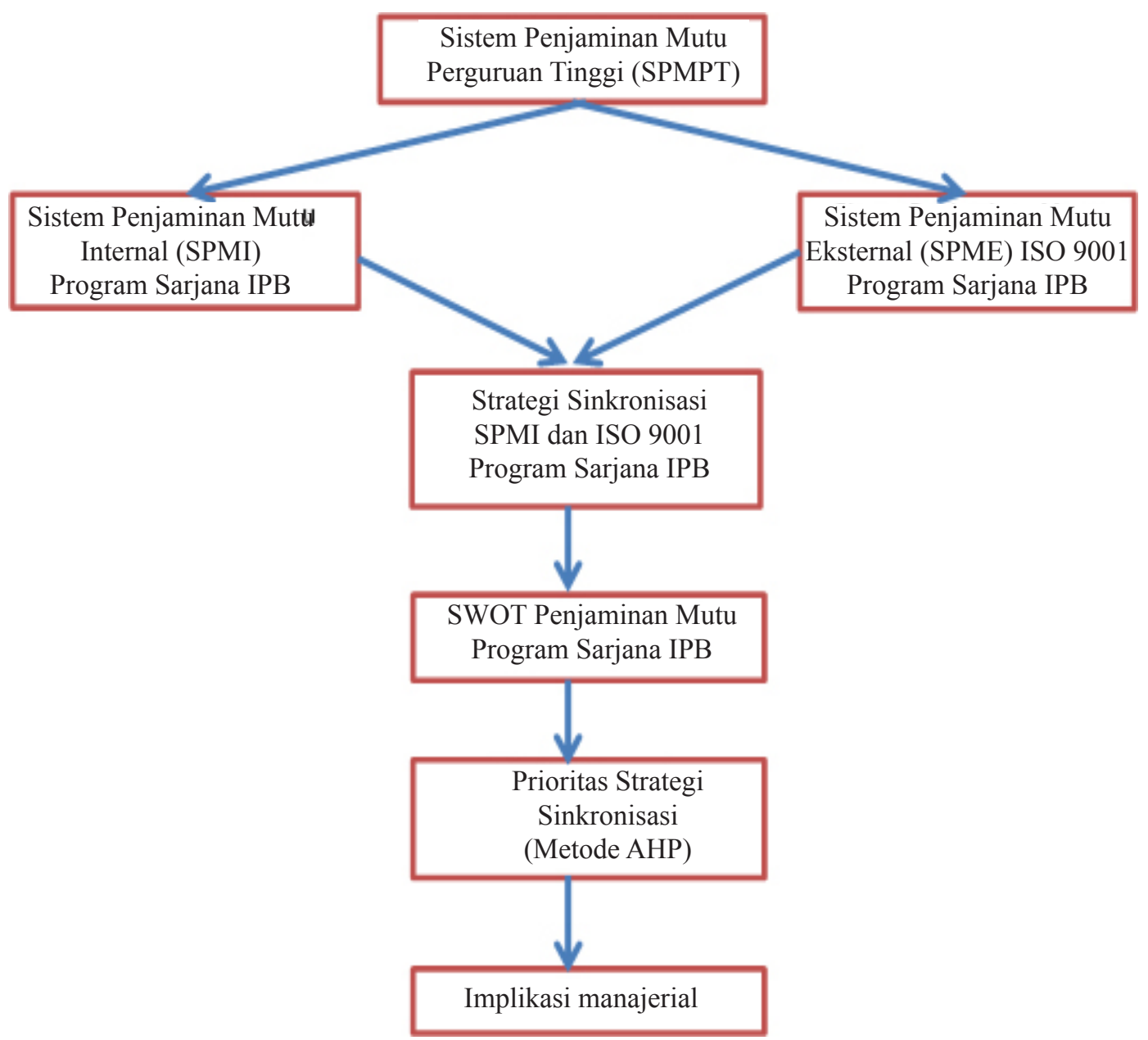

Gambar 1. Kerangka pemikiran penelitian 
Prioritas utama strategi perbaikan mutu pendidikan adalah peningkatan peringkat akreditasi dengan perbaikan SPMI, disamping perencanaan program strategis jangka panjang dan pendek guna mencapai visi, dan misi. Strategi sinkronisasi antara ISO 9001:2008 dan SPMI yang bisa dilakukan adalah penerapan SPMI secara berkelanjutan dengan klausul ISO sebagai alat dalam memenuhi pencapaian tujuh standar BAN-PT, serta dokumentasi mutu SPMI yang mengakomodir persyaratan standar klausul BAN PT dan ISO 9001:2008 (Purnama, 2015).

Penerapan SMM ISO 9001 memberikan pengaruh yang signifikan positif terhadap kinerja PT baik dari perspektif pelanggan, perspektif keuangan, perspektif bisnis internal maupun perspektif pembelajaran dan pertumbuhan (Antariksa et al. 2014). Berdasarkan evaluasi pelaksanaan SMM ISO 9001 dan SPMI telah berjalan secara terpisah, baik tim pendukung/ SDM, instrumen terkait klausul termasuk pedoman mutu, sasaran dan manual mutu, pendokumentasian, pengarsipan, dsb. Pada Tabel 1 ditunjukkan rancangan sinkronisasi SMM ISO 9001 dan SPMI.

Menurut Kurniawan et al. (2016), tidak tercapainya target yang telah ditetapkan oleh fakultas bukan semata-mata disebabkan oleh kinerja akademik fakultas yang rendah tetapi disebabkan oleh pembuatan target yang tidak terencana dengan baik. Beberapa target indikator kinerja ditetapkan dengan sangat optimistik tanpa mempertimbangkan hasil kinerja tahun-tahun sebelumnya. Fakultas sebagai GPM tidak dapat bekerja sendiri untuk meningkatkan pencapaian indikator kinerja bidang akademik. Diperlukan koordinasi yang baik dengan departemen sebagai GKM dan tim audit internal sehingga bukan hanya permasalahan yang terjadi dapat segera dicarikan solusinya tetapi juga praktek baik di masing-masing departemen dapat diadopsi ke departemen lain yang pencapaian indikator kinerjanya masih belum memuaskan. Sebagai pertimbangan integrasi SMM terkait kelebihan dan kekurangan apabila akan dilakukan penintegrasian kedua SMM tersebut ditunjukkan oleh Tabel 2.

\section{Strategi Sinkronisasi Sistem Manajemen ISO 9001 dengan SPMI untuk Menunjang SPME BAN-PT}

Frihadian et al. (2016) menyebutkan bahwa perbaikan kualitas berkelanjutan sangat penting untuk dilakukan, dengan menggali data untuk menyajikan informasi yang akurat sebagai dasar bagi pengelola dalam merumuskan strategi yang tepat. Ditunjukkan pada Tabel 3, penulis telah membuat model contoh keterkaitan antara klausul SPMI dengan ISO 9001.

\section{Pengaruh Faktor terhadap Fokus}

Hasil analisis memperlihatkan bahwa faktor utama yang berpengaruh terhadap strategi sinkronisasi implementasi SPMI dengan ISO 9001 program sarjana IPB dapat dilihat pada Gambar 2 adalah ketersediaan Instrumen SPMI dan ISO 9001 mendukung SPME BAN-PT, karena dengan instrumen baik klausul, sasaran mutu dan manual mutu yang saling menunjang akan memudahkan proses sinkronisasi kedua SMM tersebut.

Tabel 1. Sinkronisasi SPMI dan ISO 9001

\begin{tabular}{lll}
\hline \multicolumn{1}{c}{ SPMI } & \multicolumn{1}{c}{ ISO 9001 } & \multicolumn{1}{c}{ Sinkronisasi } \\
\hline $\begin{array}{l}\text { Merupakan sistem penjamin mutu } \\
\text { khusus program studi pendidikan } \\
\text { tinggi di indonesia. }\end{array}$ & $\begin{array}{l}\text { Merupakan persyaratan sistem } \\
\text { manajemen mutu umum untuk semua } \\
\text { organisasi, sehingga tidak spesifik } \\
\text { untuk dunia pendidikan. }\end{array}$ & $\begin{array}{l}\text { Klausul dalam ISO 9001 yang menunjang } \\
\text { proses penjaminan mutu PT dapat disesuaikan } \\
\text { pelaksanaan dan aplikasinya }\end{array}$ \\
$\begin{array}{l}\text { Pada pemenuhan elemen-elemen } \\
\text { akreditasi, }\end{array}$ & $\begin{array}{l}\text { Pada kesesuaian dan keefektifan } \\
\text { implementasi dari sistem manajemen } \\
\text { yang telah dibuat. }\end{array}$ & $\begin{array}{l}\text { Pemenuhan elemen standar akreditasi dapat } \\
\text { dicapai secara efektif sesuai klausul ISO 9001 }\end{array}$ \\
$\begin{array}{l}\text { Lebih terfokus kepada } \\
\text { pemenuhan standar akreditasi dari } \\
\text { pada kemampuan manajemen } \\
\begin{array}{l}\text { Terpenuhi standar elemen } \\
\text { akreditasi. }\end{array}\end{array}$ & $\begin{array}{l}\text { Pengen bisnis } \\
\text { perkendalian proses dan peningkatan }\end{array}$ & $\begin{array}{l}\text { Fokus pada manajemen proses (sesuai } \\
\text { prinsip ISO 9001) dalam pemenuhan standar } \\
\text { akreditasi }\end{array}$ \\
& & $\begin{array}{l}\text { Dalam pemenuhan target standar pada } \\
\text { akreditasi dilakukan pula prinsip-prinsip } \\
\text { pengendalian proses dan continuous } \\
\text { improvement seperti pada ISO 9001 }\end{array}$ \\
\hline
\end{tabular}




\section{Pengaruh Aktor terhadap Fokus}

Kepala KMM menjadi aktor utama dalam strategi sinkronisasi implementasi SPMI dengan ISO 9001 program sarjana IPB, seperti ditunjukkan pada Gambar 3. PT di Indonesia dan IPB khususnya pemahaman terhadap apa dan bagaimana mutu dijalankan serta ditingkatkan masih normatif, belum mendalam akan manfaat serta kerugian apabila tidak diimplementasikan secara berkesinambungan. Belum timbul budaya mutu, sehingga masih harus memerlukan banyak bimbingan dan peringatan tentang pentingnya standar, proses dan komitmen dari manajemen unit.

Tabel 2. Kelebihan dan kekurangan dari sistem manajemen mutu terintegrasi

\begin{tabular}{ll}
\hline \multicolumn{1}{c}{ Kelebihan } & \multicolumn{1}{c}{ Kekurangan } \\
\hline Persyaratan lebih sederhana (dokumentasi dan lainnya) & $\begin{array}{l}\text { Kesulitan dalam menemukan persamaan yang umum } \\
\text { Biaya pendaftaran dan auditing lebih efisien }\end{array}$ \\
$\begin{array}{l}\text { Hudit terpadu (terintegrasi) } \\
\text { Takut kehilangan pekerjaan melalui amalgamation } \\
\text { (penyatuan pekerjaan) }\end{array}$ \\
$\begin{array}{l}\text { Setiap organisasi dapat memilih apa yang harus } \\
\text { diimplementasikan }\end{array}$ \\
$\begin{array}{l}\text { Transisi yang sederhana } \\
\text { Mengurangi biaya }\end{array}$ \\
$\begin{array}{l}\text { Harmonisan tujuan operasional } \\
\text { Kesejajaran, proses dan sumberdaya di berbagai tujuan/ } \\
\text { sasaran }\end{array}$ \\
$\begin{array}{l}\text { Sangat baik untuk small business/unit kerja yang kecil } \\
\text { Mengeliminasi usaha yang tidak perlu }\end{array}$ \\
Peningkatan efektifitas dan efisiensi
\end{tabular}

Sumber: Luthfi (2011).

Tabel 2. Kelebihan dan kekurangan dari sistem manajemen mutu terintegrasi

\begin{tabular}{|c|c|c|c|}
\hline Proses bisnis & & & Klausul terkait \\
\hline \multirow[t]{2}{*}{$\begin{array}{l}\text { Ujian reguler } \\
\text { UTS/UAS }\end{array}$} & SPMI & 5.2 .9 . & $\begin{array}{l}\text { Program studi menerapkan mekanisme penjaminan mutu soal ujian dan } \\
\text { kesesuaiannya dengan isi silabus sehingga menghasilkan soal ujian yang bermutu } \\
\text { baik dan dapat mengukur kompetensi yang dirumuskan. }\end{array}$ \\
\hline & ISO 9001 & 8.2.3. & Pemantauan dan pengukuran proses \\
\hline \multirow[t]{2}{*}{$\begin{array}{l}\text { Tinjauan } \\
\text { manajemen }\end{array}$} & SPMI & 2.2.1. & $\begin{array}{l}\text { Departemen memiliki Gugus Kendali Mutu dengan tugas dan tanggung jawab } \\
\text { yang jelas dalam pengendalian mutu akademik di program studi yang berada di } \\
\text { bawah pengelolaannya. }\end{array}$ \\
\hline & ISO 9001 & 5.6 .1 & Rekaman hasil tinjauan manajemen. \\
\hline \multirow{2}{*}{$\begin{array}{l}\text { Pengendalian } \\
\text { ketidaksesuaian } \\
\text { proses }\end{array}$} & SPMI & 2.3.2. & $\begin{array}{l}\text { Departemen melaksanakan penjaringan umpan balik dari mahasiswa melalui } \\
\text { evaluasi proses belajar mengajar setiap semester. }\end{array}$ \\
\hline & ISO 9001 & 8.3 & Pengendalian produk yang tidak sesuai \\
\hline
\end{tabular}

Sumber: Luthfi (2011).

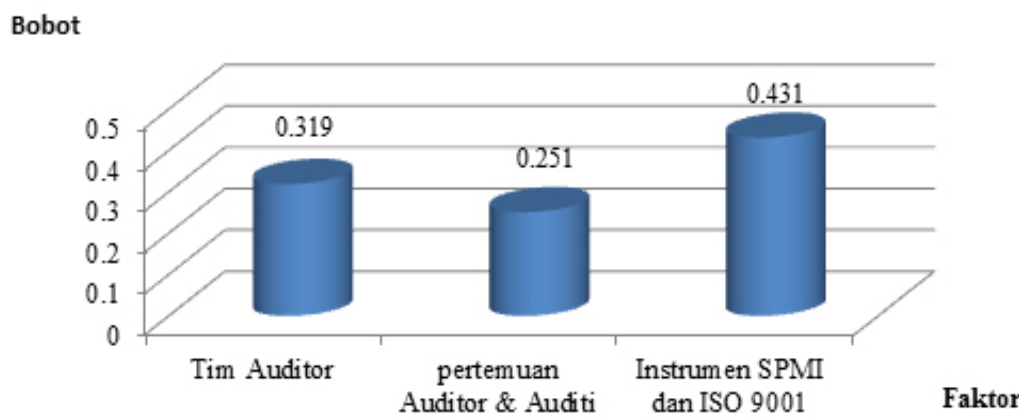

Gambar 2. Faktor-faktor yang berpengaruh terhadap strategi sinkronisasi implementasi SPMI dengan ISO 9001 program sarjana IPB 
Diikuti oleh aktor berikutnya, yaitu Rektor sebagai pimpinan tertinggi PT. Manajemen mutu pada saat ini menjadi fenomena yang memerlukan perhatian khusus bagi sebuah PT. Secara keseluruhan kepemimpinan visioner dan kinerja dosen berpengaruh secara positif dan signifikan terhadap mutu universitas. Untuk menciptakan perguruan tinggi yang bermutu maka kepemimpinan visioner dan kinerja dosen perlu mendapat perhatian yang lebih dari perguruan tinggi. Dengan demikian, pimpinan sebaiknya mengupayakan untuk bersikap empati terhadap sivitas akademika melalui perhatian yang sungguh-sungguh terhadap aspirasi dan kebutuhan semua orang-orang yang ada dalam lembaga tersebut, bersikap ramah-tamah dan sopan, melayani dengan sepenuh hati, menciptakan suasana akademik yang kondusif, menciptakan suasana yang harmonis, sikap terbuka dan suasana yang menyenangkan (Christianingsih, 2011).

\section{Pengaruh Tujuan terhadap Fokus}

Menurut para pakar (responden) yang memiliki prioritas tujuan utama adalah sinkronisasi SPMI dengan ISO 9001, seperti ditunjukkan pada Gambar 4. Hal tersebut dapat menunjang klausul kriteria standar pada SPMI, sehingga standar target dapat tercapai dengan proses serta komitmen yang terencana atau dapat diistilahkan do what you write and write what you do for the standarization target.

\section{Bobot}

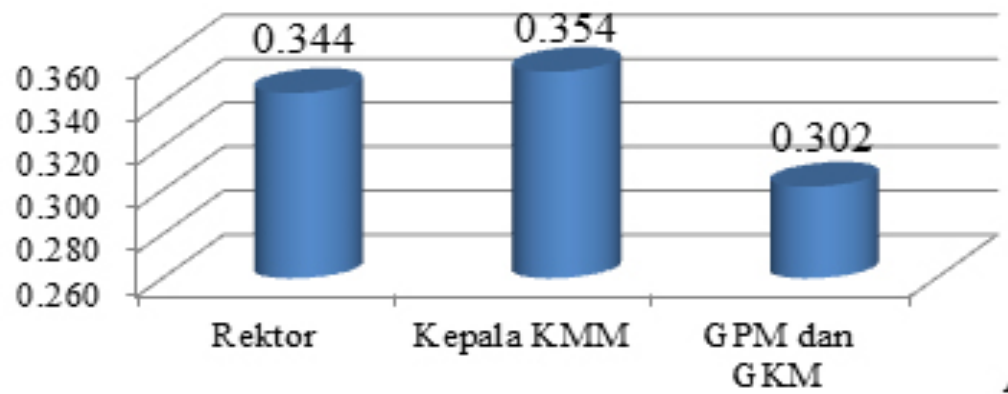

Gambar 3. Aktor yang berperan dalam strategi sinkronisasi implementasi SPMI dengan ISO 9001 program sarjana IPB (KMM (Kantor Manajemen Mutu); GPM (Gugus Penjamin Mutu) dan GKM (Gugus Kendali Mutu).

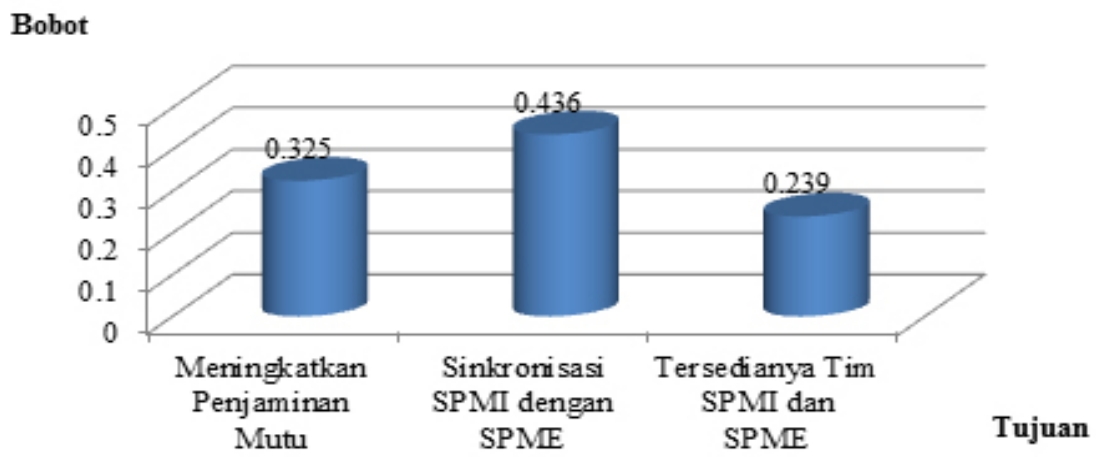

Gambar 4. Tujuan dalam strategi sinkronisasi implementasi SPMI dengan ISO 9001 Program Sarjana IPB 


\section{Alternatif Strategi}

Rancangan sinkronisasi manual mutu antara SPMI dan ISO 9001 menjadi prioritas utama yang harus dilakukan berdasarkan hasil sintesis goal, seperti ditunjukkan pada Gambar 5. Selanjutnya, apabila telah tersusun rancangan sinkronisasi kedua SMM tersebut, akan memudahkan pada pelaksana SMM serta para wakil manajemen juga dapat dengan memudah memonitor dan mengevaluasi pelaksanaannya. Apabila nantinya setelah kedua SMM tersebut terintegrasi akan menunjang pula kinerja pegawai, sesuai dengan penelitian yang dilakukan oleh Amirudin (2014), terdapat pengaruh yang signifikan antara penerapan ISO 9001: 2008 terhadap kinerja karyawan. Hal ini menunjukkan bahwa setelah penerapan ISO 9001: 2008 memiliki pengaruh terhadap peningkatan karyawan dari delapan dimensi ISO 9001: 2008 memiliki kategori baik. Secara lengkap hasil pengolahan alternatif strategi sinkronisasi kedua SMM berdasarkan metode AHP seperti ditunjukkan pada Tabel 4.

\section{Implikasi Manajerial}

Unit kerja yang akan melakukan sertifikasi ISO 9001 sebaiknya melakukan konsultasi dengan KMM IPB didampingi oleh konsultan ISO 9001 terkait manual mutu dan sasaran mutu yang sebaiknya direncanakan untuk dilaksanakan. Perlunya dukungan dan kerjasama dari lintas unit kerja yang mendukung tercapainya target standar SPMI dengan melakukan updating manual mutu sehingga memudahkan program studi dan fakultas dalam merancang dan mengimplementasikan klausul pada kedua SMM tersebut. Pimpinan institusi dan unit kerja dapat lebih intens mensosialisasikan budaya organisasi yang menunjang budaya mutu, agar selanjutnya pelaksanaan budaya mutu dapat melekat pada diri masing-masing staf PT. Karena tercapainya target standar SPMI dengan didukung pelaksanaan ISO 9001 yang memfokuskan tidak hanya pelaksanaan dokumentasi administrasi semata, tapi juga komitmen pimpinan akan tanggung jawab terhadap pelaksanaan mutu yang berkelanjutan.

\section{Bobot}

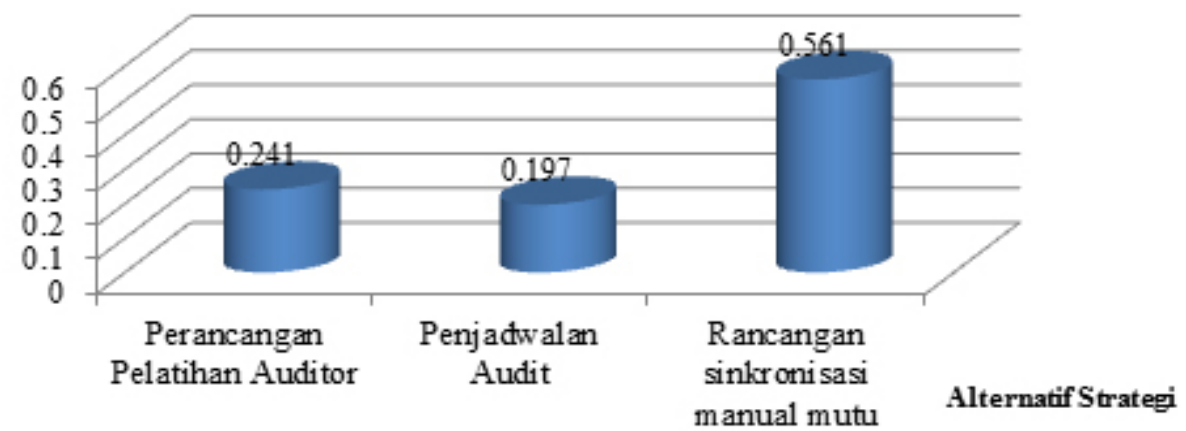

Gambar 5. Alternatif untuk strategi sinkronisasi implementasi SPMI dengan ISO 9001 program sarjana IPB

Tabel 4. Bobot dan prioritas masing-masing unsur pada hirarki strategi sinkronisasi implementasi SPMI dengan ISO 9001

\begin{tabular}{|c|c|c|c|}
\hline Level & Elemen & Bobot & Prioritas \\
\hline Fokus & \multicolumn{3}{|c|}{$\begin{array}{l}\text { strategi sinkronisasi implementasi Sistem Penjaminan Mutu Internal (SPMI) dengan ISO } 9001 \text { program } \\
\text { sarjana IPB }\end{array}$} \\
\hline \multirow[t]{3}{*}{ Faktor } & Ketersediaan instrumen SPMI dan ISO 9001 mendukung SPME BANPT & 0,431 & 1 \\
\hline & Ketersediaan tim auditor SPMI dan ISO 9001 & 0,319 & 2 \\
\hline & Ketersediaan waktu pertemuan tim auditor dan auditi & 0,251 & 3 \\
\hline \multirow[t]{3}{*}{ Aktor } & Kepala KMM & 0,354 & 1 \\
\hline & Rektor & 0,344 & 2 \\
\hline & GPM dan GKM & 0,302 & 3 \\
\hline \multirow[t]{3}{*}{ Tujuan } & Sinkronisasi klausul SPMI dengan ISO 9001 & 0,436 & 1 \\
\hline & Meningkatkan penjaminan mutu & 0,325 & 2 \\
\hline & Tersedianya tim spmi dan ISO 9001 & 0,239 & 3 \\
\hline \multirow{3}{*}{$\begin{array}{l}\text { Alternatif } \\
\text { Strategi }\end{array}$} & Rancangan sinkronisasi manual mutu antara SPMI dan ISO 9001 & 0,561 & 1 \\
\hline & Perancangan pelatihan auditor SPMI dan ISO 9001 & 0,241 & 2 \\
\hline & Penjadwalan audit yang rutin dan komprehensif & 0,197 & 3 \\
\hline
\end{tabular}




\section{KESIMPULAN DAN SARAN}

\section{Kesimpulan}

Pada pengkajian pelaksanaan SMM SPMI dan ISO 9001 pada FEMA IPB masih berjalan secara terpisah. Hal ini terlihat dari penyimpanan dan pendokumentasian. Selanjutnya, adanya gap antara klausul yang sebenarnya terkait, juga POB dan sasaran mutu yang sebenarnya adalah ranah lintas unit kerja. Variabel penyebab diantaranya adalah masih belum memahami bahwa klausul pada ISO 9001 sesungguhnya dapat menunjang klausul SPMI. Oleh karena itu, apabila dilaksanakan dengan sinkronisasi maka pada pelaksanaan prosesnya sesuai ISO 9001, hakikat target adalah standarisasi pada SPMI.

Dari tabel kesesuaian antara klausul SPMI dengan ISO 9001, terlihat bahwa apa yang telah dijalankan pada klausul ISO 9001 dapat diklaim menunjang pencapaian target pada standar SPMI terkait yang berkesesuaian. Ditambah masukan dari para pakar tentang prioritas strategi sinkronisasi kedua SMM tersebut. Dengan dmeikian, akan menunjang SPME BAN-PT sehingga pencapaian akreditasi unggul program studi dan institusi dapat teraih dengan lebih efisien dan efektif.

\section{Saran}

Saran untuk pimpinan institusi adalah dapat mengkoordinasikan semua pimpinan fakultas yang telah menerapkan ISO 9001 agar melakukan pula sinkronisa sehingga pelaksanaan beberapa SMM pada unit kerjanya tetap dapat bersinergi untuk mendukung SPMI. Diperlukan pula penelitian lebih lanjut dengan SMM lebih dari dua model selain SPMI dan ISO 9001 seperti Asean University Network (AUN) serta ISO Lab 17025 secara bersamaan.

\section{DAFTAR PUSTAKA}

Amirudin. 2014. Evaluasi penerapan ISO 9001:2008 di lingkungan UIN Syarif Hidayatullah Jakarta. Jurnal Etikonomi 13(1): 35-50.

Antariksa WF, Surachman, Setiawan M. 2014. Pengaruh penerapan sistem manajemen mutu ISO 9001:2008 di perguruan tinggi terhadap kinerja balanced scorecard (Studi Kasus pada Universitas Brawijaya). Jurnal Aplikasi Manajemen 12(3):399-406.
Asy'ari H. 2015. Perbandingan sistem manajemen mutu ISO 9001:2008, standard BAN- PT dan total quality management di UIN Maulana Malik Ibrahim Malang. Jurnal Pendidikan Islam 4(1):141-157. https://doi.org/10.14421/ jpi.2015.41.141-157.

Christianingsih E. 2011. Manajemen mutu perguruan tinggi (Studi tentang kemimpinan visioner dan kinerja dosen terhadap mutu perguruan tinggi swasta di Kota Bandung). Jurnal Manajerial 9(18):31-41.

Frihadian Z, Purwito A dan Sitanggang IS. 2016. Perbaikan kualitas berkelanjutan penyelenggaraan akademik program sarjana ilmu komputer FMIPA IPB. Jurnal Aplikasi Bisnis dan Manajemen 2(2):207-217. https:// doi.org/10.17358/JABM.2.2.207.

Gumiandari S. 2013. Komitmen pimpinan dalam pelaksanaan penjaminan mutu perguruan tinggi (Studi kasus IAIN Syekh Nurjati Cirebon). Jurnal Holistik 14(2):27-56.

Hendartho D. 2014. Analisis implementasi sistem manajemen mutu ISO 9001:2008 pada Sekolah Tinggi Ilmu Administrasi Mandala Indonesia. Jurnal Transparansi 6(2):124-138.

Kardoyo. 2011. Analisis penjaminan mutu fakultas ekonomi: pencapaian sasaran mutu akademik dan kesesuaian prosedur akademik dengan standar mutu ISO 9001:2008. Jurnal Pendidikan Ekonomi Dinamika Pendidikan 9(2):108-118.

Kurniawan Y, Purwito A, Nurani TW. 2016. Pencapaian indikator kinerja bidang akademik program sarjana pada Fakultas Perikanan dan Ilmu Kelautan Institut Pertanian Bogor dalam perspektif penjaminan mutu. Jurnal Aplikasi Bisnis dan Manajemen 2(3):258-269. https:// doi.org/10.17358/JABM.2.3.258.

Luthfi TH. 2011. Perancangan sistem manajemen mutu terintegrasi dengan metode pendekatan proses dan pedoman dokumentasi: untuk program studi di perguruan tinggi Indonesia [tesis]. Jakarta: Universitas Indonesia.

Marimin, Maghfiroh N. 2010. Aplikasi Teknik Pengambilan Keputusan dalam Manajemen Rantai Pasok. Ed ke-4. Bogor: IPB Press.

Mekić E, Göksu A 2014. Implementation of ISO 9001:2008 \& standards for accreditation at private university in Bosnia and Herzegovina. European Researcher 75(5):947-961.

Muafi, Nilmawati. 2014. Budaya mutu dan implementasi ISO 2008: 9001 serta dampaknya terhadap 
komitmen organisasional. Jurnal Dinamika Manajemen 5(1):33-47.

Palupi YE, Maarif S, Affandi J. 2017. Efektivitas pelaksanaan program dinamika kelompok pada diklat fungsional auditor. Jurnal Aplikasi Bisnis dan Manajemen 3(1): 23-34.

Panday R. 2014. Strategi peningkatan mutu perguruan tinggi untuk penguatan daya saing menghadapi masyarakat ekonomi Asia Tenggara: Studi Kasus. Proceedings SNEB 2014: hlm. 1-6.

Pillay H, Kimber M. 2009. Quality assurance in higher education: for whom and of what?. International Journal of Management in Education 3(3/4): 270-281. https://doi.org/10.1504/ IJMIE.2009.027349.

Purnama A. 2015. Strategi peningkatan mutu pendidikan melalui sinkronisasi akreditasi BAN PT dan ISO 9001:2008 (Studi kasus:Universitas Sahid Jakarta) [tesis]. Bogor: Institut Pertanian Bogor.

Purwanti E, Wiyono BB, Sunandar A. 2015. Implementasi sistem manajemen mutu ISO
9001:2008 dalam meningkatkan kualitas lulusan. Jurnal Manajemen Pendidikan 24(6):547-553.

Saaty TL. 2008. Decision making with the analytic hierarchy process. International Journal Services Sciences 1(1):83-98. https://doi.org/10.1504/ IJSSCI.2008.017590.

Saaty TL. 1993. Pengambilan Keputusan Bagi Para Pemimpin (Terjemahan). Jakarta: Pustaka Binaman Pr.

Sivaram NM, Devadasan S.R., Murugesh R. 2013. Conceptualisation for implementing total productive maintenance through the ISO 9001:2008 standard-based quality management system. South African Journal of Industrial Engineering 24(2):33-46. https://doi. org/10.7166/24-2-494.

Umiyati. 2015. Pengaruh sistem manajemen mutu ISO 9001:2008 dan partisipasi penyusunan anggaran terhadap kinerja manajerial. Jurnal Etikonomi 14(1):87-112.https://doi.org/10.15408/etk. v14i1.2218. 